\title{
Recovery, Health, and Job Performance: Effects of Weekend Experiences
}

\author{
Charlotte Fritz and Sabine Sonnentag \\ Technical University of Braunschweig
}

\begin{abstract}
This study extended research on respites by examining the extent to which experiences during the weekend contribute to health and job performance after the weekend. Longitudinal data including 3 measurement occasions from 87 emergency service workers indicated that nonwork hassles, absence of positive work reflection, and low social activity during the weekend predicted burnout and poor general well-being after the weekend. Weekend experiences also predicted different aspects of job performance after the weekend. The results reveal practical implications for individual and organizational optimization of recovery processes. Suggestions for future research on specific recovery processes and their effects on individual health and performance are discussed
\end{abstract}

Keywords: recovery, health, job performance, weekend, well-being

Many employees use their weekend as an opportunity to recover from stress experienced at work. During weekends, individuals typically do not face their daily job demands, which allows for regeneration and the regain of resources. These replenished resources will then have short-term effects on individual health and job performance at the beginning of the following work week. Empirical findings already indicated that respites from work foster positive affective experiences and performance when back at work (Sonnentag, 2003; Westman \& Eden, 1997; Westman \& Etzion, 2001). However, Eden (2001, p. 123) mentioned that "there has been almost no study of the restorative value of ... the weekend ... nor any research devoted to increasing its contribution to on-the-job productivity." Thus, we still need to investigate the role of the weekend as a regularly occurring respite in fostering health and on-the-job experiences after the weekend. It seems that it is not just the amount of leisure time that matters. The quality of the respite experience may play an impor-

Charlotte Fritz and Sabine Sonnentag, Institute of Psychology, Work, Organizational, and Social Psychology Unit, Technical University of Braunschweig, Braunschweig, Germany.

This study is part of Charlotte Fritz's dissertation. We thank Martin Hackenberg and Anke Kullack for their help with data collection and Sandra Ohly for helpful comments on earlier drafts of this article.

Correspondence concerning this article should be addressed to Charlotte Fritz, Institute of Psychology, Work, Organizational, and Social Psychology Unit, Technical University of Braunschweig, Spielmannstrasse 19, 38092, Braunschweig, Germany. E-mail: c.fritz@tu-bs.de tant role in the recovery process (Etzion, Eden, \& Lapidot, 1998; Lounsbury \& Hoopes, 1986; Westman \& Eden, 1997). Understanding recovery processes during an employee's weekend will add to more general research on individual recovery. Thus, the goal of this study was to investigate the effects of specific weekend experiences on health and performance after the weekend, namely, burnout and general well-being on one hand and task performance and proactivity on the other hand. In our study, we apply a longitudinal design with three measurement points assessing health and performance before and after the weekend and weekend experiences during the weekend.

\section{The Recovery Process}

Daily job demands draw on the employee's resources and may lead to strain reactions that can reduce health and performance (e.g., Caplan \& Jones, 1975; Demerouti, Bakker, de Jonge, Janssen, \& Schaufeli, 2001; Totterdell, Spelten, Smith, Barton, \& Folkard, 1995). Impaired health and performance can be described as a lack of individual resources that can be reestablished during a weekend when the employee is no longer confronted with the usual work demands. In this line of thinking, Hobfoll's $(1989,1998)$ conservation of resources (COR) theory claims that an individual aspires to preserve, protect, and build resources. Resources are characterized as objects, conditions, personal characteristics, or energies that have specific importance for the individual. Stress occurs when a person is threatened with re- 
source loss, actual loss of resources, or a failing gain of resources after resource investment. In the work context, burnout can indicate a lack of resource gain "following a significant resource investment of time, energy, lost opportunities, and borrowing time and intimacy to support work" (Hobfoll, 2001, p. 347). Time away from work, however, may enhance wellbeing and reduce burnout symptoms. Recent research has already used COR theory to explain the effects of respites on work-related and nonwork-related outcomes (Eden, 2001). The absence of work-related demands during a respite allows one to invest in new resources and to initiate resource gain. For example, Westman and Eden (1997) assumed that exhausted resources can be replenished through specific experiences during a respite such as relaxation, reconnecting with family and friends, practicing control, or developing a sense of mastery.

Applying these assumptions to the present study, we investigated how an employee's weekend influences his or her health and performance after the weekend. Because work demands normally are removed from the individual during the weekend, it allows for regeneration (Meijman \& Mulder, 1998), resulting in reduced strain and enhanced health and performance when the individual is back at the workplace. On basis of the COR model, it can be argued that the individual can use the weekend to rebuild resources that may be needed when back at work. However, sometimes during the weekend, rebuilding resources is not possible but, instead, even more resources are consumed. This could be the case if the individual faces a high amount of nonwork hassles during the weekend.

\section{Individual Health}

There is increasing empirical evidence that respites have a positive effect on individual health (Lounsbury \& Hoopes, 1986; Westman \& Eden, 1997; Westman \& Etzion, 2001). Health has been conceptualized in several ways. The aspects of health we are focusing on in this study are burnout and general well-being. Burnout is characterized as a psychological strain resulting from the accumulation of chronic daily stressors at work (Etzion, 1984). Demerouti and colleagues (Demerouti, Bakker, Nachreiner, \& Schaufeli, 2001) differentiate between two dimensions of burnout, namely, exhaustion and disengagement. Exhaustion is a result of a prolonged physical, affective, and cognitive strain. In the context of our study, we prefer this definition to the one by Maslach and colleagues (Maslach, Jackson, \&
Leiter, 1996), which mainly focuses on the affective aspect of exhaustion (Demerouti, Bakker, Nachreiner, \& Schaufeli, 2001). We think that in the context of our sample, namely, emergency medical workers, it is useful to measure exhaustion that goes beyond affective experiences. Disengagement "refers to distancing oneself from one's work and experiencing negative attitudes toward the work object, work content, or one's work in general" (Demerouti, Bakker, Nachreiner, \& Schaufeli, 2001, p. 501). In addition to burnout as a directly job-related strain reaction, we studied the effects of weekend experiences on general well-being. Because the weekend can function as an opportunity to recover from recent job demands, we assumed that the level of general wellbeing is influenced by specific experiences during the weekend.

\section{Job Performance}

One goal of recovery from work demands is to ensure performance when returning back to work. Thus, in addition to positive effects for the individual, certain amounts of time off the job are beneficial for the organization as well. The replenishment of resources during a weekend leads to a high availability of resources when the employee is back at work. The resource could then be invested to gain even more resources such as positive feedback or knowledge.

Job performance can be seen as a multidimensional concept (Campbell, McCloy, Oppler, \& Sager, 1993). In our study we focused on task performance and proactive behaviors at work. Task performance refers to behaviors "that are recognized by formal reward systems and are part of the requirements as described in job descriptions" (Williams \& Anderson, 1991, p. 606). Individual experiences during the weekend may increase resources that can be visible in increased task performance after the weekend.

Proactive behaviors include activities that are particularly future oriented. This type of behavior is associated with "taking initiative in improving current circumstances or creating new ones; it involves challenging the status quo rather than passively adapting to present conditions" (Crant, 2000, p. 436). Proactive performance is particularly important for an organization because it is not possible to specify in advance all the behaviors necessary for the achievement of organizational goals (George, 1991). Because today's organizations undergo frequent changes, they need employees who act flexibly and proactively. One form of 
proactive behavior is personal initiative (Frese, Fay, Hilburger, Leng, \& Tag, 1997). Personal initiative is "a behavior syndrome resulting in an individual's taking an active and self-starting approach to work and going beyond what is formally required in a given job" (Frese, Kring, Soose, \& Zempel, 1996, p. 38). Frese and colleagues assume that personal initiative is a unidimensional construct with five components: "It 1 . is consistent with the organization's mission, 2 . has a long-term focus, 3. is goal directed and action-oriented, 4. is persistent in the face of barriers and setbacks, and 5. is self-starting and proactive" (Frese et al., 1996, p. 38). Another concept associated with proactive behavior that has been studied lately in the context of recovery is pursuit of learning (Sonnentag, 2003). Pursuit of learning refers to seeking learning opportunities with the goal of higher competence and mastery of new situations (VandeWalle, 1997). For example, it includes searching for situations in which one can develop new knowledge and skills. Because increased knowledge and skills can have an impact on individual performance and organizational outcomes, it is important to find out how off-work experiences can increase individual learning behavior at work. In addition, research suggested that high levels of stress reduce individual learning at work (Holman \& Wall, 2002; Taris \& Kompier, in press; Taris, Kompier, de Lange, Schaufeli, \& Schreurs, 2003). Thus, recovery processes during an employee's weekend may have an impact on learning-related behaviors when the employee is back at work. In summary, specific experiences during an individual's weekend may increase resources that then are invested into proactivity after the weekend.

\section{Weekend Experiences}

In our study, we focused on three different weekend experiences that we assumed to have an impact on health and job performance after the weekend. On the basis of COR theory, we examined both negative experiences that additionally draw on the individual's resources and more positive experiences that help to regain and build up lost resources. Therefore, we studied nonwork hassles as weekend experiences that have a negative impact, and social activity and positive work reflection as experiences that have a positive impact on health and job performance after the weekend.

\section{Nonwork Hassles}

Nonwork hassles refer to "constellations of related and ongoing stressors experienced in day-to-day life" (Lepore \& Evans, 1996, p. 353). Outside work, such stressors can be accumulated housework, conflicts with the partner or family, or sudden problems with the car. Research revealed that a high amount of daily hassles impairs individual health (Bolger, DeLongis, Kessler, \& Schilling, 1989). Because such hassles appear recurrently in everyday life (Bolger et al., 1989), they may be influential during the weekend, too. If we think of the weekend as a time to recover from work demands and to build new resources, a high amount of hassles during the weekend may impair necessary recovery processes. In addition to hindering the establishment of new resources, nonwork hassles during the weekend may also act as an emotional drain that even consumes individual resources (Hobfoll, 1998). As a result, physical and emotional resources are lacking when the employee is back at work. This lack of resources may be evident in high levels of strain and poor general well-being after the weekend. The employee will still feel exhausted and may even show psychosomatic symptoms. In addition, lack of individual resources may lead to less effort in everyday work tasks or to reduced proactive behavior at work. Thus, we hypothesized that nonwork hassles during the weekend are negatively related to health and job performance after the weekend.

Hypothesis 1: Nonwork hassles experienced during the weekend are positively related to burnout and poor general well-being after the weekend.

Hypothesis 2: Nonwork hassles experienced during the weekend are negatively related to task performance and proactivity after the weekend.

\section{Social Activity}

Besides negative effects of weekend experiences such as nonwork hassles, there may be experiences that foster health and performance after the weekend. One such experience is involving oneself in social activities. Spending time with other people can be one way of recovering from work demands (Sonnentag, 2001). Social activities comprise activities such as meeting people one likes and pursuing activities with others. Such activities imply the chance of social 
support, which in return is beneficial for individual health (Viswesvaran, Sanchez, \& Fisher, 1999). Hobfoll (1998) referred to social resources as, for example, close relationships with friends or being involved in organizations with other people who share the same interests. Westman (1999) surmised that reconnecting with family and friends during leisure time helps rebuild worn-out physical and emotional resources, thus enabling more resource gains. A weekend may give an individual time to uphold his or her social network and to draw support from it. As a result, the individual will feel less exhausted and drained.

Additionally, during social activities, job demands are removed from the individual so that recovery processes can occur. Even for employees with a high amount of social interaction at the workplace, social activity during leisure time can be beneficial. One can assume that during private social activity, the individual needs to apply less emotion regulation than during social interactions at work (Grandey, 2000). Social activities during the weekend additionally can generate new individual resources. The replenished resources then become apparent in individual health when one is back at work. In addition, these newly established resources can be invested back into work. This may then be evident in a high task performance level or a greater amount of proactive behaviors at work. Therefore, we expected health and performance to benefit from social activity during the weekend.

Hypothesis 3: Social activity during the weekend is negatively related to burnout and poor general well-being after the weekend.

Hypothesis 4: Social activity during the weekend is positively related to task performance and proactivity after the weekend.

\section{Positive Work Reflection}

Another potentially important weekend experience is positive work reflection. Reflecting about one's job in a positive way may reduce burnout and enhance general well-being and performance after the weekend. One can argue that reflecting positively about one's job acts as a form of reappraisal of a possibly stressful work situation (Lazarus \& Folkman, 1984). A positive reappraisal of one's work situation leads to a reduction in stress reactions, which when applied to the context of our study may mean that individual resources are restored.
Westman (1999) assumed that reflection could be one way to replenish lost resources, which then may facilitate further resource gains. Positive work reflection refers to thinking about the positive aspects of one's job and realizing what one likes about it. For example, becoming aware of the positive features of one's job may enhance the feeling that what one does has sense and significance. Reflecting about the tasks already fulfilled and the goals achieved at work may also have a positive effect on self-efficacy and as a result may increase individual well-being. Positively thinking about one's work may also lead to the development of new goals and plans concerning the individual work. The application of these work-related goals and plans that act as individual resources may then lead to higher task performance and additional proactive behaviors at work. Thus, although distancing oneself from the job during leisure time may be beneficial for regeneration processes (Sonnentag \& Bayer, in press), reflecting positively about the job may replenish individual resources and enhance subsequent feelings of health as well as performance at work

Hypothesis 5: Positive work reflection during the weekend is negatively related to burnout and poor general well-being after the weekend.

Hypothesis 6: Positive work reflection during the weekend is positively related to task performance and proactivity after the weekend.

\section{Method}

To test our hypotheses and to allow for causal inferences, we used a longitudinal design. We measured our outcome variables (i.e., health and performance) after the weekend at the beginning of the following work week. We assessed the weekend experiences at the end of the weekend on Sunday evening. To examine the effect of weekend experiences on changes in our outcome variables, we assessed health and performance also before the weekend at the end of the preceding work week and controlled for these preweekend variables in the analyses.

\section{Sample and Procedure}

The sample of our study included 87 employees of emergency medical services in different German cities. Participants were trained in medical assistance and fulfilled two main work tasks. First, they transported ill persons from home to medical institutions and back to their homes and assisted medically, when needed. Second, they were called in medical emergencies (e.g., a car accident) and assisted medical doctors in treating wounded patients. We reached participants by phoning the head of each organization and 
asking them to participate in our study. After giving their consent for participation, supervisors estimated the number of respondents in their own organization. Accordingly, we sent out survey packages including instructions, three separate surveys (one for each measurement point), and a stamped return envelope. Participants provided self-reports at three different points in time: The first survey was completed at the end of the work week on Thursday or Friday evening (Time 1); the second survey on Sunday evening, thus at the end of the weekend (Time 2); and the third survey at the beginning of the following work week on Monday or Tuesday evening (Time 3). We later included the day of the third measurement as a control variable in our analyses. At the first and third measurement times, participants were asked to fill in the survey at the end of a work day so that data on health and performance on that specific day were gathered. Completed surveys were sent back directly to the researchers to ensure participants' confidentiality.

Altogether, 512 surveys were sent out. Of the 102 surveys returned (response rate $=19.92 \%$ ), 15 were not included in the analyses because of missing data. Out of the final sample of 87 study participants, $83(95.4 \%)$ respondents were male. On average, the participants were 32.88 years old and had 9.72 years of job experience. Of the sample, $5.7 \%$ of the respondents had no job degree, $80.5 \%$ had completed a 2 - to 3 -year professional training, 9.2\% had completed a professional training and an additional advanced degree, and 3.4\% had a university degree. The average working time per week was $42.26 \mathrm{hr}$, with an average of $4.13 \mathrm{hr}$ of overtime per week.

\section{Measures}

\section{Weekend Experiences}

Study participants completed all items referring to weekend experiences at the end of the weekend (Time 2). The items were answered on 5-point rating scales ranging from 1 (not true at all) to 5 (very true).

Nonwork hassles. We measured the number of nonwork hassles experienced during the weekend by adapting nine items from a measure developed by Bolger et al. (1989). The scale referred to private stressors during the weekend, such as a lot of work at home, demands made by friends or relatives, and conflicts with the partner or other persons. Cronbach's alpha was .73.

Social activity. Social activity was assessed with three items. The items referred to pursuing activities with other persons and cultivating relationships during the weekend. Cronbach's alpha was .76.

Positive work reflection. Positive work reflection was gauged with three items. The items referred to how much participants thought about positive aspects of his or her job during the weekend. Cronbach's alpha was .90 .

\section{Health}

Items referring to burnout and general well-being were rated on 4-point rating scales, with high scores indicating a high amount of symptoms. Participants responded to the items with respect to the present day.
Burnout. Burnout before the weekend (Time 1) was quantified with the Oldenburg Burnout Inventory (Demerouti, Bakker, Kantas, \& Vardakou, 2003). Exhaustion (e.g., feelings of being emotionally drained during work) and disengagement (e.g., feelings of losing internal relationship with one's work) were each measured with eight items. Cronbach's alphas were .81 for exhaustion and .71 for disengagement. Burnout after the weekend (Time 3) was measured with the same scales as before the weekend. Cronbach's alphas were .86 for exhaustion and .76 for disengagement. To test the factor structure of the burnout scale, we conducted confirmatory factor analyses for burnout at Time 1 and Time 3. We examined whether the two-factor model was superior to a one-factor model. We used a chi-square difference test to find out which model best fitted the data. In case of burnout at Time 1, the two-factor model provided a fit superior to that of a onefactor model $\left(\Delta \chi^{2}=85.01, d f=1, n=86\right)$. A similar pattern emerged at Time $3\left(\Delta \chi^{2}=36.01, d f=1, n=83\right)$, again showing a superiority of the two-factor model.

General well-being. We measured general well-being before the weekend with 12 items from the General Health Questionnaire (Goldberg, 1978), which referred to minor psychosomatic complaints. Cronbach's alpha was .81. We used the same measure to assess general well-being after the weekend at Time 3. Cronbach's alpha was .84 .

\section{Job Performance}

All items for task performance and proactivity were answered on 5-point rating scale ranging from 1 (not true at all) to 5 (very true).

Task performance. We measured task performance at Time 1 with five items from the Williams and Anderson scale. Cronbach's alpha was .78. We measured task performance at Time 3 with the same items. Cronbach's alpha was .83 .

Proactivity. We assessed two aspects of proactivity before the weekend: personal initiative and pursuit of learning. More specifically, we measured personal initiative at Time 1 with seven items developed by Frese and colleagues (Frese et al., 1996). Items referred to taking initiative and actively approaching and solving problems at work. Cronbach's alpha was .70. We used the same scale to measure personal initiative after the weekend at Time 3. Cronbach's alpha was .86. To measure pursuit of learning before the weekend, we adapted items from the learning goal orientation scale developed by VandeWalle (1997). Study participants completed five pursuit-oflearning items that referred to the individual's search for opportunities to develop new skills and knowledge. Cronbach's alpha was .82 . The same scale was used to measure pursuit of learning after the weekend at Time 3 . Cronbach's alpha was .91.

To ensure that both proactivity measures assess related but different aspects of performance, we again conducted confirmatory factor analyses for Time 1 and Time 3 . Results revealed that a two-factor model fitted the data better than a one-factor model at Time $1\left(\Delta \chi^{2}=50.83, d f=1, n=86\right)$ and Time $3\left(\Delta \chi^{2}=94.99, d f=1, n=85\right)$. 


\section{Control Variables}

Control variables included into our data analyses were dispositional negative affect and the day of the third measurement.

Negative affect. Negative affect was measured at Time 1 with 10 items from the Positive and Negative Affect Schedule (Watson, Clark, \& Tellegen, 1988). Participants were asked on a 5-point rating scale how they felt "in general" referring to 10 adjectives indicating negative affect. Cronbach's alpha was .86.

Day of third measurement (Time 3). We assumed that participants might show differences in health and job performance depending on the day of the third measurement (Monday vs. Tuesday). For example, research revealed that perceptions of autonomy were significantly lower on Monday than on other weekdays (Reis, Sheldon, Gable, Roscoe, \& Ryan, 2000). This as well as other perceptions may have an impact on subsequent health and performance. Therefore we controlled for day of the week when measuring health and performance after the weekend.

\section{Results}

Means, standard deviations, variable intercorrelations, and alpha coefficients are presented in Table 1 . To test our hypotheses, we conducted hierarchical regression analyses, thereby entering dispositional negative affect and day of the third measurement as control variables into the equation in the first step, and health and job performance before the weekend in the second step. More specifically, we entered burnout at Time 1 when predicting burnout at Time 3, task performance at Time 1 when predicting task performance at Time 3, and so forth. In the third step, we added nonwork hassles, positive work reflection, and social activity during the weekend. Tables 2 and 3 indicate that different weekend experiences account for significant additional variance in the outcome variables.

\section{Health}

\section{Burnout}

With regard to burnout, we found the following pattern: Dispositional negative affect entered in the first step significantly explained variance in exhaustion and disengagement. This indicates that employees high in negative affect reported higher burnout after the weekend. Exhaustion and disengagement before the weekend significantly predicted postweekend scores of exhaustion and disengagement, respectively. In addition, weekend experiences significantly contributed to both burnout dimensions. However, of the experiences measured, only positive work reflec- tion was significantly negatively related to exhaustion, suggesting that employees who positively reflected about their job during the weekend experienced lower exhaustion after the weekend. In contrast, disengagement after the weekend was significantly predicted by all the weekend experiences. These results show that low disengagement after the weekend was associated with fewer nonwork hassles, higher levels of positive work reflection, and more social activity during the weekend.

\section{General Well-Being}

Similar outcomes emerged with regard to general well-being. Results revealed that poor general wellbeing at Time 1 entered in the second step significantly contributed to poor general well-being after the weekend. Nonwork hassles were significantly positively related to poor general well-being after the weekend, meaning that employees who faced more stressors during the weekend reported lower general well-being after the weekend. Additionally, social activity during the weekend significantly predicted the degree of general well-being after the weekend. In more detail, employees who were involved in more social activity during the weekend reported better general well-being after the weekend. In summary, specific experiences during the weekend contributed to poor general well-being after the weekend. This contribution resulted over and above the contribution of negative affect and well-being before the weekend.

\section{Job Performance}

\section{Task Performance}

Regarding effects of the control variables, the day of the third measurement significantly predicted task performance after the weekend, indicating that employees reported higher levels of task performance on Monday than on Tuesday. Task performance before the weekend entered in the second step accounted for significant variance in task performance after the weekend. Weekend experiences significantly contributed to task performance after the weekend. Thus, nonwork hassles experienced during the weekend were negatively related to task performance after the weekend, which means that individuals who faced a high amount of nonwork stressors during the weekend showed lower performance in their everyday work tasks at the beginning of the following work week. Social activity showed a positive relationship 


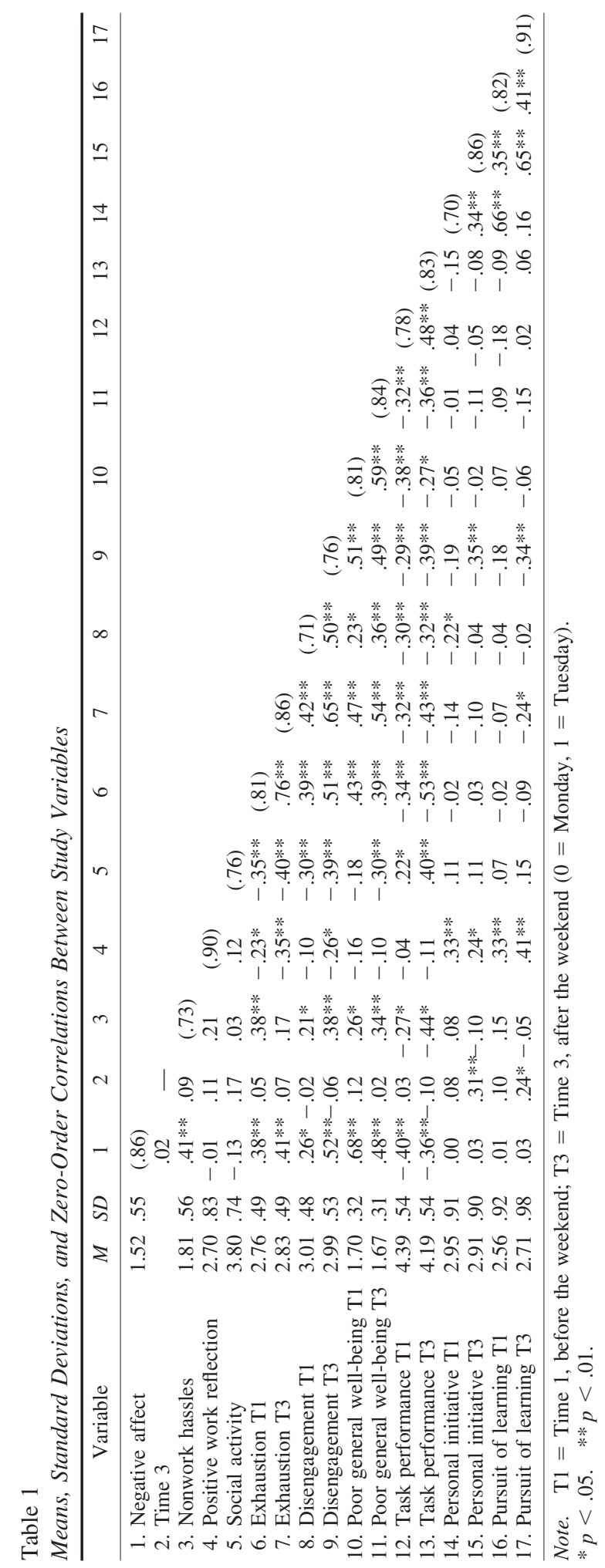


Table 2

Hierarchical Regression of Health on Weekend Experiences

\begin{tabular}{|c|c|c|c|c|c|c|c|c|c|}
\hline \multirow[b]{2}{*}{ Variable } & \multicolumn{3}{|c|}{ Exhaustion (Time 3) } & \multicolumn{3}{|c|}{$\begin{array}{l}\text { Disengagement } \\
\quad \text { (Time 3) }\end{array}$} & \multicolumn{3}{|c|}{$\begin{array}{l}\text { Poor general well-being } \\
\text { (Time 3) }\end{array}$} \\
\hline & $\beta$ & $\Delta R^{2}$ & $R^{2}$ & $\beta$ & $\Delta R^{2}$ & $R^{2}$ & $\beta$ & $\Delta R^{2}$ & $R^{2}$ \\
\hline Step 1: Control variables & & $.17 * *$ & $.17 * *$ & & $.28 * *$ & $.28 * *$ & & $.23 * *$ & $.23 * *$ \\
\hline Negative affect & $.20 *$ & & & $.32 * *$ & & & .06 & & \\
\hline Time 3 & .02 & & & -.02 & & & -.06 & & \\
\hline \multicolumn{10}{|l|}{ Step 2: Outcome variable at Time 1} \\
\hline Exhaustion & $.63 * *$ & $.44 * *$ & $.61 * *$ & & & & & & \\
\hline Disengagement & & & & $.26^{* *}$ & $.13 * *$ & $.41 * *$ & & & \\
\hline Poor general well-being & & & & & & & $.46 * *$ & $.14^{* *}$ & $.37 * *$ \\
\hline Step 3: Weekend experiences & & $.06^{* *}$ & $.67 * *$ & & $.14 * *$ & $.55^{* *}$ & & $.09 *$ & $.46 *$ \\
\hline Nonwork hassles (Time 2) & -.08 & & & $.26^{* *}$ & & & $.24 *$ & & \\
\hline Positive work reflection (Time 2) & $-.17 *$ & & & $-.25 * *$ & & & -.03 & & \\
\hline Social activity (Time 2) & -.14 & & & $-.25 * *$ & & & $-.21 *$ & & \\
\hline
\end{tabular}

Note. Beta weights refer to the full model, Time 3: $0=$ Monday, $1=$ Tuesday.

$* p<.05 . \quad * * p<.01$

with task performance after the weekend, indicating that spending time with important others during the weekend enhances task performance when being back at work.

\section{Proactivity}

With regard to personal initiative, the third measurement point entered into the regression analysis in the first step showed a significant regression weight, meaning that participants showed significantly more personal initiative on Tuesday than on Monday. Personal initiative before the weekend significantly pre- dicted personal initiative after the weekend. Experiences during the weekend overall did not account for additional variance in personal initiative after the weekend.

Pursuit of learning before the weekend was a strong predictor of pursuit of learning after the weekend. Weekend experiences accounted for additional variance in pursuit of learning after the weekend. Specifically, nonwork hassles showed a negative regression weight, implying that a high number of nonwork hassles during the weekend was associated with lower pursuit of learning after the weekend. Additionally, positive work reflection revealed a sig-

Table 3

Hierarchical Regression of Job Performance on Weekend Experiences

\begin{tabular}{|c|c|c|c|c|c|c|c|c|c|}
\hline \multirow[b]{2}{*}{ Variable } & \multicolumn{3}{|c|}{$\begin{array}{l}\text { Task performance } \\
\text { (Time 3) }\end{array}$} & \multicolumn{3}{|c|}{$\begin{array}{l}\text { Personal initiative } \\
\text { (Time 3) }\end{array}$} & \multicolumn{3}{|c|}{$\begin{array}{l}\text { Pursuit of learning } \\
\quad \text { (Time 3) }\end{array}$} \\
\hline & $\beta$ & $\Delta R^{2}$ & $R^{2}$ & $\beta$ & $\Delta R^{2}$ & $R^{2}$ & $\beta$ & $\Delta R^{2}$ & $R^{2}$ \\
\hline Step 1: Control variables & & $.15^{* *}$ & $.15 * *$ & & .07 & .07 & & .05 & .05 \\
\hline Negative affect & -.03 & & & .10 & & & .12 & & \\
\hline Time 3 & $-.18 *$ & & & $.25^{*}$ & & & .18 & & \\
\hline \multicolumn{10}{|l|}{ Step 2: Outcome variable at Time 1} \\
\hline Task performance & $.30 * *$ & $.15^{* *}$ & $.30 * *$ & & & & & & \\
\hline Personal initiative & & & & $.28 * *$ & $.10 * *$ & $.17 * *$ & & & \\
\hline Pursuit of learning & & & & & & & $.31 * *$ & $.15 * *$ & $.20 * *$ \\
\hline Step 3: Weekend experiences & & $.20 * *$ & $.50 * *$ & & .06 & $.23 * *$ & & $.13^{* *}$ & $.33 * *$ \\
\hline Nonwork hassles (Time 2) & $-.33 * *$ & & & $-.23^{*}$ & & & $-.25^{*}$ & & \\
\hline Positive work reflection (Time 2) & -.06 & & & .17 & & & $.33^{* *}$ & & \\
\hline Social activity (Time 2 ) & $.38 * *$ & & & .04 & & & .08 & & \\
\hline
\end{tabular}

Note. Beta weights refer to the full model; Time 3: $0=$ Monday, $1=$ Tuesday.

$* p<.05 . \quad * * p<.01$. 
nificant positive regression weight, indicating that higher positive work reflection during the weekend led to higher reported pursuit of learning after the weekend.

\section{Additional Analyses}

One may argue that an employee's health mediates the relationship between individual respite experiences and job performance. Research has revealed that recovering from work demands increases individual health (Westman \& Eden, 1997; Westman \& Etzion, 2001). In addition, research has found significant relationships between individual health and job performance (e.g., Parker \& Kulik, 1995). More specifically, in a longitudinal study, Wright and Cropanzano (1998) found a significant effect of emotional exhaustion on low job performance. Applied to the context of our study, this means that specific weekend experiences may have an effect on health, which in turn may be associated with job performance. Thus, we investigated whether health after the weekend, in our case burnout and poor general well-being, mediated the relationship between individual weekend experiences and job performance after the weekend.

To test for mediation, we used Baron and Kenny's (1986) analytical approach. We first investigated the relationships between weekend experiences and health, between weekend experiences and job performance, and between health and job performance. The first two relationships already have been shown by testing Hypotheses 1-6, with the exception of personal initiative. To study the third relationship, we regressed each aspect of job performance on all the aspects of health we had measured. Analyses revealed that exhaustion was significantly related to task performance $(\beta=-.26, p<.01)$, indicating that individuals who reported lower feelings of exhaustion showed higher levels of task performance. Further, disengagement was significantly associated with both aspects of proactivity, namely personal initiative $(\beta=-.42, p<.01)$ and pursuit of learning $(\beta=-.39, \mathrm{p}<.01)$, suggesting that individuals who experienced higher levels of disengagement after the weekend showed lower levels of proactive behavior at work. General well-being was not associated with any reports of job performance. We then used additional regression models to investigate the pattern of mediation for the significant predictors (exhaustion and disengagement). In the first case we tested the mediation of exhaustion on task performance, entering control variables and task performance at Time 1 into the regression in Steps 1 and 2, respectively, and weekend experiences and exhaustion in Steps 3 and 4 , respectively. If the beta weights for weekend experiences are significant in the third but not significant or substantially reduced in the fourth step, we have a pattern consistent with mediation. Exhaustion did not mediate the relationship between social activities (beta weight changed from $\beta=.33, p<.01$, to $\beta=.26, p<.01$ ), positive work reflection (beta weight changed from $\beta=-.05, p<.57$, to $\beta=$ $-.19, p<.06$ ), or nonwork hassles (beta weight changed from $\beta=-.24, p<.02$, to $\beta=-.25, p<$ .02 ) and task performance. In the second case, we studied the possible mediation of disengagement on pursuit of learning. Analyses showed that disengagement did not mediate the relationship between social activities (which changed from $\beta=.07, p<.50$, to $\beta=-.06, p<.57$ ), positive work reflection (beta weight changed from $\beta=.34, p<.01$, to $\beta=.27$, $p<.01$ ), or nonwork hassles (beta weight changed from $\beta=-.15, p<.18$, to $\beta=-.06, p<.54)$ and pursuit of learning. We did not test for a mediation of disengagement in the relationship between weekend experiences and personal initiative, because weekend experiences were not significantly related to personal initiative after the weekend in the first place. In summary, results referring to mediation effects showed that burnout or general well-being did not mediate the relationship between weekend experiences and job performance after the weekend.

\section{Discussion}

The primary objective of this study was to examine if specific experiences during a weekend significantly contribute to health and performance after the weekend. Our data partially supported our hypotheses. Specifically, nonwork hassles were significantly related to disengagement and poor general well-being after the weekend. These results support those of Bolger et al. (1989) and suggest that additional nonwork hassles during the weekend may impair individual recovery processes. As a consequence, disengagement after the weekend is higher, and general well-being decreases. However, exhaustion-an often studied work-related strain reaction-does not seem to be influenced by nonwork hassles during the weekend. With regard to job performance, nonwork hassles experienced during the weekend were negatively related to task performance and pursuit of learning after the weekend. This result may imply that facing a lot of nonwork hassles during the weekend consumes resources that otherwise can be in- 
vested into task performance as well as into proactivity after the weekend. Additionally, nonwork hassles during the weekend may impair the regeneration of resources necessary for high performance during the following work week.

Analysis further revealed that reflecting positively about the job during the weekend had an effect on exhaustion and disengagement, indicating that thinking positively about one's job during leisure time decreases feelings of burnout. These findings may indicate that weekend experiences that refer to workrelated issues may be more strongly related to workrelated health than to general well-being. This explanation is supported by our finding that positive work reflection did not contribute to general well-being after the weekend. Further, thinking about one's job in a positive way during the weekend was positively related to pursuit of learning after the weekend, indicating that reflecting positively about the job seems to enhance a person's striving to learn something new at work. It may be that thinking positively about one's work fosters the development of goals and plans. The realization of such goals and plans may then be reflected in a person's willingness to learn when back at the workplace. In addition, with respect to the interface between the work and nonwork domain, results on positive work reflection suggest no segmentation in the form of a separation between the two domains (Edwards \& Rothbard, 2000). In contrast, thinking positively about work during nonwork time is beneficial for health and to some extent for job performance.

Finally, social activity during the weekend was negatively associated with disengagement and poor general well-being after the weekend. Although social activity did not have a significant effect on exhaustion, results pointed to the hypothesized direction, and there was a strong bivariate relationship between the two variables. Thus, involving oneself in social activities during the weekend decreases burnout and fosters general well-being after the weekend. It appears as if spending time with important others rebuilds resources that pay off after the weekend. These findings support research indicating that spending time with other people can be one way of recovering from work demands (Sonnentag, 2001; Westman, 1999). In addition, social activity during leisure time was positively associated with task performance after the weekend. Thus, social activity may replenish resources that-besides having positive effects on health - promote individual fulfillment of everyday work tasks when returning to the workplace. The processes of social activity may thus par- allel those of social support (Viswesvaran et al., 1999). It is possible that social activity during offwork time becomes less important if social support at work is high. Future research should investigate the role of social activity and its relationship with social support, referring to different employee groups and time frames. In contrast to our predictions, social activity during the weekend did not have an effect on proactivity. Again, the question is how far these results depend on the sample we studied. It is possible, that in the case of emergency medical service workers, the resources that are built up through social activity during the weekend are used for the fulfillment of everyday work tasks but have low potential for proactivity. Here, further research clearly seems necessary.

In summary, referring to indicators of individual health, our results extend previous research on respites from work and their effect on individual health (Eden, 2001; Lounsbury \& Hoopes, 1986; Sonnentag, 2001; Westman \& Eden, 1997). In this study, we shed some light on the specific processes underlying changes in burnout and general well-being during a weekend. Our results indicate that specific weekend experiences have an effect on burnout and general well-being after the weekend, although the specific processes that lead to relationships between specific weekend experiences and aspects of health obviously need to be further investigated.

It is surprising that the weekend experiences we measured were not a strong predictor of personal initiative. However, results referring to nonwork hassles and positive work reflection point to the hypothesized direction. The failure to find a significant increase in explained variance in personal initiative after the weekend may, on the one hand, be a consequence of the small sample size and, on the other hand, result from the specific work conditions of our sample. Working for an emergency medical service may not leave the freedom to show personal initiative within 1 day. In contrast, such a job may even include strict procedures that for safety reasons should not be challenged in the short term. Possibilities for showing personal initiative may depend to a great extent on the situation and may not so much be under the control of the employee. Accordingly, in our study, personal initiative at work after the weekend was not related to individual experiences during the weekend. In contrast, two of the three weekend experiences we measured were significantly related to proactivity in the form of pursuit of learning, indicating that how employees experience their weekend has an impact on their willingness to learn something at work. In 
the case of our sample, it may also imply that in contrast to seemingly missing opportunities for showing personal initiative, there are quite a few opportunities for employees to actively approach learning-related situations. Overall, with regard to job performance, this study extends the still rare research on the effects of respites on job performance (Westman \& Aharon-Madar, 1998). Focusing on the underlying recovery processes, we found that weekend experiences have an influence on at least some aspect of job performance after the weekend. This effect includes the fulfillment of everyday work tasks and the active approach toward learning opportunities. However, our results further indicate that the specific processes that underlie the relationship between recovery on one hand and health and performance on the other hand need to be better understood and clarified.

In additional analyses, we tested if burnout and general well-being mediated the relationship between weekend experiences and job performance. Such a pattern of results would imply that weekend experiences lead to changes in health, which then will be related to performance at work. However, we did not find any mediation. Thus, changes in job performance after the weekend are not a consequence of changes in health but seem to be influenced independently by specific weekend experiences. However, there could be other mediators, for example, motivational processes, that explain the effect of weekend experiences on subsequent job performance. It might be that specific weekend experiences increase work motivation, which in turn affects job performance.

\section{Strengths and Limitations}

As with any study, the present study has a number of shortcomings. First, the low response rate in our study could mean that our sample differed significantly from the population in several aspects. However, this response rate seems reflective of the work conditions of medical emergency service employees: They only have one free 2-day weekend per month. On the one hand, this could mean that possible participants did not have a 2-day weekend within the time of data gathering. On the other hand, we assume that a lot of possible participants were not willing to fill out the survey during their rare weekend. Furthermore, results from a recent meta-analysis (Schalm \& Kelloway, 2001) suggest that study findings do not seem to be affected by the size of the response rate.

Second, as we only used self-reports, we have to consider that common method variance may have inflated our results. However, results of Crampton and Wagner (1994) indicate that criticism of the use of self-report often seems overestimated. In addition, the differential pattern of relationships lends support to the assumption that common method variance is not a major limitation of this study. A third shortcoming of our study is the small and very specific sample, namely employees of emergency medical services. This sample might show different relationships between the main variables than would be the case in other employee groups, which brings into question the generalizability of our findings. However, this study was the first to focus on the relationship between specific weekend experiences and jobrelated outcomes. In this context, it seems sensible to study the relationships with a focus on a smaller and more specific context in which as much "natural" variance as possible can be controlled for. This approach clearly calls for further research that may be able to generalize our findings to other work settings.

Although the limitations should be taken into account, there are strengths in this study that may foster the relevance of our results. First, we applied a longitudinal design including three measurement points. Thus, the inference of causality is much stronger than in cross-sectional data. Second, because we assessed health and performance before and after the weekend, we can control for each variable at Time 1 when predicting the same variable at Time 3 . After adding these and other control variables, weekend experiences still explained variance in the dependent variables.

This research has several new features. First, we studied employees' experiences during the weekend, a time frame that to our knowledge has not been studied in the context of work yet. Second, we focused on specific experiences during the weekend, namely nonwork stressors, positive job reflection, and social activity. Overall, our results stress the importance of investigating specific leisure time experiences as they may be relevant for individual as well as organizational outcomes.

\section{Implications and Future Research}

Our study has theoretical as well as practical implications. In terms of theoretical discussions, our results suggest looking at specific recovery processes if one wants to understand the effects of respites on employees' health and performance. First, as the picture is not totally clear yet, future research should further investigate the causal relationships between on-the-job and off-the-job experiences. Future stud- 
ies may incorporate the approach taken in the present study by focusing on specific experiences during a respite and their impact on subsequent individual health and performance. One additional experience that may be important in the context of the weekend is the amount and quality of sleep or rest time. High levels of sleep and rest time may replenish resources that become visible in subsequent health and job performance. Second, we need to examine the generalizability of our results to other time frames. Although weekend experiences may be effective in reducing acute stress reactions, longer respites may be necessary to reduce symptoms of chronic job stress and to fill up individual resources in a more long-term perspective (Westman \& Eden, 1997). A vacation, for example, leaves more room for other activities to foster the recovery process than the evening or a weekend. Third, we need to study the generalizability of our results to other employee groups. Maybe future research will show that different occupational groups need different leisure activities to recover. Fourth, vacation research found that the positive effects of this off-the-job time fade out quickly (Eden, 2001). Future research should investigate if this phenomenon also appears in the context of a weekend and if there are experiences on the job and at home that may delay fade-out processes. We hope that our study will provide an impetus for future research on these topics.

Knowing the impact of experiences during leisure time on health and behaviors on the job additionally has practical implications for individuals and organizations. In reference to the results in this study, employees should try to enhance positive social activity during off-job time. In addition, employees should take some time during the weekend to reflect about the positive aspects of their job by developing goals and plans. Finally, when facing nonwork hassles during the weekend, individuals should actively search for recovery possibilities to optimize effects of positive leisure experiences and maximize individual recovery processes.

In addition, organizations should try to design jobs in a way that allows recovery from weekly work demands during a weekend. In other words, job demands should not exceed certain levels so that individuals can completely recover from these demands during a free weekend. Furthermore, organizations should consider possible reductions in workload or allow explicit breaks after intensive work. Enhanced recovery can then reduce employees' burnout symptoms and foster general well-being. In addition, suc- cessful recovery processes will be beneficial for job performance.

\section{References}

Baron, R. M., \& Kenny, D. A. (1986). The moderatormediator variable distinction in social psychology research: Conceptual, strategic, and statistical considerations. Journal of Personality and Social Psychology, 51, 1173-1182.

Bolger, N., DeLongis, A., Kessler, R. C., \& Schilling, E. A. (1989). Effects of daily stress on negative mood. Journal of Personality and Social Psychology, 57, 808-818.

Campbell, J. P., McCloy, R. A., Oppler, S. H., \& Sager, C. E. (1993). A theory of performance. In N. Schmitt \& W. C. Borman (Eds.), Personnel selections in organizations (pp. 35-70). San Francisco: Jossey-Bass.

Caplan, R. D., \& Jones, K. W. (1975). Effects of work load, role ambiguity, and type A personality on anxiety, depression, and heart rate. Journal of Applied Psychology, 60, 713-719.

Crampton, S. M., \& Wagner, J. A., III. (1994). Perceptpercept inflation in microorganizational research: An investigation of prevalence and effect. Journal of Applied Psychology, 79, 67-76.

Crant, J. M. (2000). Proactive behavior in organizations. Journal of Management, 26, 435-462.

Demerouti, E., Bakker, A. B., de Jonge, J., Janssen, P. P. M., \& Schaufeli, W. B. (2001). Burnout and engagement at work as a function of demands and control. Scandinavian Journal of Work Environment and Health, 27, 279-286.

Demerouti, E., Bakker, A. B., Kantas, A., \& Vardakou, I. (2003). The convergent validity of two burnout instruments: A multitrait-multimethod analysis. European Journal of Psychological Assessment, 18, 296-307.

Demerouti, E., Bakker, A. B., Nachreiner, F., \& Schaufeli, W. B. (2001). The job demands-resources model of burnout. Journal of Applied Psychology, 86, 499-512.

Eden, D. (2001). Vacations and other respites: Studying stress on and off the job. In C. L. Cooper \& I. T. Robertson (Eds.), International review of industrial and organizational psychology (Vol. 16, pp. 121-146). New York: Wiley.

Edwards, J. R., \& Rothbard, N. P. (2000). Mechanisms linking work and family: Clarifying the relationship between work and family constructs. Academy of Management Review, 25, 178-199.

Etzion, D. (1984). Moderating effect of social support on the stress-burnout relationship. Journal of Applied Psychology, 69, 615-622.

Etzion, D., Eden, D., \& Lapidot, Y. (1998). Relief from job stressors and burnout: Reserve service as a respite. Journal of Applied Psychology, 83, 377-585.

Frese, M., Fay, D., Hilburger, T., Leng, K., \& Tag, A. (1997). The concept of personal initiative: Operationalization, reliability and validity in two German samples. Journal of Occupational and Organizational Psychology, 70, 139-161.

Frese, M., Kring, W., Soose, A., \& Zempel, J. (1996). Personal initiative at work: Differences between East and West Germany. Academy of Management Journal, 39, $37-63$. 
George, J. M. (1991). State or trait: Effects of positive mood on prosocial behavior. Journal of Applied Psychology, 76, 299-307.

Goldberg, D. (1978). Manual of the General Health Questionnaire. London: Oxford University Press.

Grandey, A. A. (2000). Emotion regulation in the workplace: A new way to conceptualize emotional labor. Journal of Occupational Health Psychology, 5, 95-110.

Hobfoll, S. E. (1989). Conservation of resources: A new attempt at conceptualizing stress. American Psychologist, 44, 513-524.

Hobfoll, S. E. (1998). Stress, culture, and community: The psychology and philosophy of stress. New York: Plenum Press.

Hobfoll, S. E. (2001). The influence of culture, community, and the nested-self in the stress process: Advancing conservation of resources theory. Applied Psychology: An International Review, 50, 337-421.

Holman, D. J., \& Wall, T., D. (2002). Work characteristics, learning-related outcomes, and strain: A test of competing direct effects, mediated, and moderated models. Journal of Occupational Health Psychology, 7, 283-301.

Lazarus, R. S., \& Folkman, S. (1984). Stress, appraisal, and coping. New York: Springer.

Lepore, S. J., \& Evans, G. W. (1996). Coping with multiple stressors in the environment. In M. Zeidner \& N. S. Endler (Eds.), Handbook on coping: Theory, research, application (pp. 350-377). New York: Wiley.

Lounsbury, J. W., \& Hoopes, L. L. (1986). A vacation from work: Changes in work and nonwork outcomes. Journal of Applied Psychology, 71, 392-401.

Maslach, C., Jackson, A. P., \& Leiter, M. P. (1996). Maslach Burnout Inventory: Third edition. Palo Alto, CA: Consulting Psychologists Press.

Meijman, T. F., \& Mulder, G. (1998). Psychological aspects of workload. In P. J. D. Drenth, H. Thierry, \& C. J. de Wolff (Eds.), Handbook of work and organizational psychology (Vol. 2, pp. 5-33). Hove, England: Psychology Press.

Parker, P. A., \& Kulik, J. A. (1995). Burnout, self- and supervisor-rated job performance, and absenteeism among nurses. Journal of Behavioral Medicine, 18, 581599.

Reis, H. T., Sheldon, K. M., Gable, S. L., Roscoe, J., \& Ryan, R. M. (2000). Daily well-being: The role of autonomy, competence, and relatedness. Personality and Social Psychology Bulletin, 26, 419-435.

Schalm, R. L., \& Kelloway, E. K. (2001). The relationship between response rate and effect size in occupational health psychology. Journal of Occupational Health Psychology, 6, 160-163.

Sonnentag, S. (2001). Work, recovery activities, and individual well-being: A diary study. Journal of Ocсираtional Health Psychology, 6, 196-210.

Sonnentag, S. (2003). Recovery, work engagement, and proactive behavior: A new look at the interface between nonwork and work. Journal of Applied Psychology, 88, $518-528$

Sonnentag, S., \& Bayer, U. (in press). Switching off mentally: Predictors and consequences of psychological detachment from work during off-job time. Journal of Occupational Health Psychology.

Taris, T. W., \& Kompier, M. A. J. (in press). Job demands, job control, strain and learning behavior: Review and research agenda. In A. G. Antoniou \& C. L. Cooper (Eds.), Research companion to organizational health psychology. London: Edward Elgar Press.

Taris, T. W., Kompier, M. A. J., de Lange, A. H., Schaufeli, W. B., \& Schreurs, P. J. G. (2003). Learning new behavior patterns: A longitudinal test of Karasek's active learning hypothesis among Dutch teachers. Work \& Stress, 17, $1-20$.

Totterdell, P., Spelten, E., Smith, L., Barton, J., \& Folkard, S. (1995). Recovery from work shifts: How long does it take? Journal of Applied Psychology, 80, 43-57.

VandeWalle, D. (1997). Development and validation of a work domain goal orientation instrument. Educational and Psychological Measurement, 57, 995-1015.

Viswesvaran, C., Sanchez, J. I., \& Fisher, J. (1999). The role of social support in the process of work stress: A meta-analysis. Journal of Vocational Behavior, 54, 314334

Watson, D., Clark, L. A., \& Tellegen, A. (1988). Development and validation of brief measures of positive and negative affect: The PANAS scales. Journal of Personality and Social Psychology, 54, 1063-1070.

Westman, M. (1999, August). Gain and loss spirals: Applying Hobfoll's COR theory to respite research. Paper presented at the Academy of Management meeting, Chicago, IL.

Westman, M., \& Aharon-Madar, M. (1998, May). The impact of vacation on stress, burnout, and performance. Paper presented at the Seventh International Conference on Social Stress, Budapest, Hungary.

Westman, M., \& Eden, D. (1997). Effects of a respite from work on burnout: Vacation relief and fade-out. Journal of Applied Psychology, 82, 516-527.

Westman, M., \& Etzion, D. (2001). The impact of vacation and job stress on burnout and absenteeism. Psychology and Health, 16, 595-606.

Williams, L. J., \& Anderson, S. E. (1991). Job satisfaction and organizational commitment as predictors of organizational citizenship and in-role behaviors. Journal of Management, 17, 601-617.

Wright, T. A., \& Cropanzano, R. (1998). Emotional exhaustion as a predictor of job performance and voluntary turnover. Journal of Applied Psychology, 83, 486-493.

Received December 7, 2003

Revision received August 19, 2004

Accepted October 23, 2004 